\title{
Positive and Negative Syndrome Scale as a long- term outcome measurement tool in patients receiving clozapine ODT- A Pilot Study
}

\author{
Gollapudi SHANKAR, Carmen NATE.
}

\begin{abstract}
${ }^{*}$
Objective: This pilot, twelve-week, open-label study examined the effect of clozapine orally disintegrating tablet or ODT in patients with schizophrenia and schizoaffective disorder utilizing Positive and Negative Syndrome Scale (PANSS) as a long-term outcome measurement tool. Methods: The final study sample consisted of nineteen subjects who were residents a long-term care psychiatric facility in Pomona, California. Subjects were using clozapine ODT (FazaClo®) at the most clinically effective dosage depending on their symptoms and at the discretion of the psychiatrist and psychopharm consultant. PANSS were administered at baseline, week-4, week-8 and week-12. Paired sample t-tests were used to calculate the statistical significance of the mean differences for scores at baseline and week-12. Results: Mean differences from baseline indicated significant improvement on total score, as well as positive, negative, cognitive and general psychopathology subscales after twelve weeks of treatment. The greater average reduction in the negative syndrome subscale across the twelve weeks possibly illustrates the ability of clozapine ODT in improving negative symptoms, including cognitive function which is their ability to participate in their personal care and creative expressions in dance, arts, games, poetry to a greater extent their overall, quality of life and living along with the effect on positive symptoms.

Conclusion: Overall, clozapine proved to affect a broad range of psychopathology including cognitive functions in this schizophrenic sample.
\end{abstract}

Keywords: Antipsychotic Agents. Quality of Life. Treatment Outcome. United States.

\begin{abstract}
RESUMEN
Objetivo: Este estudio piloto de 12 semanas examinóel efecto de comprimidos oralmente dispersables (OD) de clozapina en pacientes con esquizofrenia o desordenes esquizo-afectivos utilizando la escala Positive and Negative Syndrome Scale (PANSS) como herramienta de medida de resultados.

Métodos: La muestra final de estudio consistió en 19 individuos que residían en una clínica siquiátrica de larga estancia en Pomona, California. Los individuos estaban utilizando clozapina OD (FazaClo®) a la dosis más efectiva clínicamente dependiendo de sus síntomas y a discreción del psiquiatra y el consultor psicofarmacéutico. Se administró el PANS Sal inicio, en las emana 4, semana 8 y semana 12 . Se utilizaron t-test apareados para calcular la significación estadística de las diferencias de las medias para las puntuaciones basales y en la semana 12 . Resultados: Las diferencias medias del valor inicial indicaron mejora significativa en la puntuación total, así como en las subescalas positiva, negativa y de psicopatología general después de 12 semanas de tratamiento. La mayor media de reducción en la subescala negativa tras las 12 semanas posiblemente ilustra la capacidad de la clozapina OD para mejorar los síntomas negativos, incluyendo la función cognitiva que es la capacidad de participare $\mathrm{n}$ su cuidado personal y las expresiones creativa sen baile, arte, juegos, poesía y en mayor escalas u calidad de vida general ye 1 sobrellevar los efectos en los síntomas positivos. Conclusión: En general, la clozapina demostró afectar un amplio margen del a psicopatología, que incluye las funciones cognitiva sen esta muestra de esquizofrénicos.
\end{abstract}

Palabras clave: Antipsicóticos. Calidad de vida. Resultados del tratamiento. Estados Unidos.

\section{(English)}

\section{INTRODUCTION}

Approximately $20 \%$ of the two million Americans who suffer from schizophrenia are considered refractory because they receive modest benefit from conventional antipsychotic medications. Clozapine is the only atypical antipsychotic drug indicated for treatment-refractory schizophrenia based on its established superior efficacy. It is the only atypical 
antipsychotic that is approved for the reduction of suicidal behaviour. ${ }^{1}$ Patients who are refractory to treatment are typically more disabled as compared to other patients with schizophrenia and have a history of poor adherence which may contribute to relapse, adequate treatment can be challenging. Orally disintegrating tablets (ODT) of clozapine, offers a better way to increase adherence and improve control of psychotic symptoms. ${ }^{2}$

The Positive and Negative Syndrome Scale (PANSS) is an established psychiatric rating system that is an operationalized, drug-sensitive instrument that offers balanced representation of positive and negative symptoms and estimates their relationship to one another and to global (or general) psychopathology. The reliability and stability of the PANSS was tested previously in a large study. ${ }^{3}$ Previous studies have shown that clozapine treatment significantly improve PANSS scores in patients with schizophrenia or schizoaffective disorder after 12 and 14 weeks of treatment. ${ }^{4,5}$

In this study, PANSS is conducted on patients receiving clozapine ODT in a free-standing mental health facility to determine long term patient outcomes in cognition as related to creativity and quality of life.

The main purpose of the prospective study is to use the Positive and Negative Syndrome Scale (PANSS) as a tool to evaluate changes in positive, negative and cognitive symptoms in patients with schizophrenia or schizoaffective disorder who are receiving clozapine orally disintegrating tablet or ODT (FazaClo®).

\section{METHODS}

\section{Subjects}

Inclusion Criteria: Study subjects were selected by reviewing clients' medical charts in Olive Vista, a long-term care psychiatric facility, in Pomona, California. Clients were included in the study if they were on either on clozapine ODT or clozapine, and also have the following inclusion criteria: (1) diagnosis of schizophrenia or schizoaffective disorder diagnosed based on DSM-IV by the facility's psychiatrist; (2) have been placed on clozapine ODT by the facility's psychiatrist or had been on the study medication before coming to this facility due to refractory to previous antipsychotic medication treatments. Subjects from $18-65$ years of age were included. Subjects currently using other typical or atypical antipsychotic medications are not excluded.

Exclusion Criteria: Clients allergic to clozapine ODT or clozapine, or intolerant to the study medications due to severe adverse drug reactions were excluded.

The study received IRB approval; and informed consents were obtained from each of the study subjects. All subjects were on dosages of clozapine ODT that were titrated by the facility psychiatrist to achieve maximum clinical benefits not based on PANSS scores. Other than encouraging the subjects in their creative expressions of music, art, drama, games, poetry, humor, ensure their need for medication compliance and their sense of spiritual value no treatment intervention was necessary to carry out the study except the allowance of dosage reduction of study medications in the event of adverse drug reaction.

\section{Design and Assessment}

Positive and Negative Syndrome Scale (PANSS) composes of 3 components: Positive $(P)$, Negative $(\mathrm{N})$ and cognitive or General Psychopathology (G).

Positive syndrome is composed of symptoms such as delusions, hallucinations and disorganized thinking. Negative syndrome is characterized by deficits in cognitive, affective, and social functions, including blunting of affect and passive withdrawal. General Psychopathology is composed of many deficits in cognition such as disorientation, poor attention, lack of insight and active social avoidance.

Positive and Negative subscales each contain 7 items (P1 - P7, N1 - N7); General Psychopathology subscale contains 16 items with the major emphasis on cognition (G 1 - G16) (Table 1).

Each item is scored from 1-7 based on the presence and severity of symptoms: $(1=$ absent, 2 $=$ minimal, $3=$ mild, $4=$ moderate, $5=$ moderate severe, 6 = severe, 7 = extreme).

\begin{tabular}{|l|l|l|}
\hline \multicolumn{2}{|l|}{ Table 1: Positive and Negative Syndrome Scale (PANSS) } \\
\hline Positive (p) & Negative (n) & Cognitive or general psychopathology (g) \\
\hline P1. delusions & N1. Blunted affect & G1. somatic concern \\
P2. conceptual disorganization & N2. emotional withdrawal & G2. anxiety \\
P3. hallucinatory behavior & N3. poor rapport & G3. guilt feelings \\
P4. excitement & N4. passive / apathetic social & G4. tension \\
P5. grandiosity & withdrawal & G5. mannerism and posturing \\
P6. suspiciousness / persecution & N5. difficulty in abstract & G6. depression \\
P7. hostility & thinking & G7. motor retardation \\
& N6. lack of spontaneity and & G8. uncooperativeness \\
& flow of conversation & G9. unusual thought content \\
& N7. stereotyped thinking & G10. disorientation \\
& & G11. poor attention \\
& & G12. lack of judgment and insight \\
& & G13. disturbing of volition \\
& G14. poor impulse control \\
& G15. preoccupation \\
& G16. active social avoidance \\
\hline
\end{tabular}


Each item on the PANSS is accompanied by a complete definition as well as thorough anchoring criteria for all 7 rating points. Based on the above scoring method, the least scores for the Positive and Negative subscales are 7 points each, and 16 points for the cognitive category; for a combined total of minimum 30 points. Most points for each category are 49, 49 and 112 for Positive, Negative, and cognition, respectively; for a combined total of maximum 210 points.

Subjects were interviewed by the facility's psychiatrist and Psychiatric pharmacist at baseline and every 4 weeks thereafter (baseline, week-4, week-8 and week-12). The interviewer asked questions pertaining to PANSS and also encouraged subjects to discuss their history, circumstances surrounding their hospitalization, their current life situation and their symptoms. The objective of this process is to establish rapport and allow subjects to express areas of concern. During each clinical interview, subject's affective, motor, behavioral and cognitive functions were observed. Their ability to participate by empowering them through their creative expressions and their integrative and interactive functions were also directly observed by the interviewers.

The duration of each clinical interview was 15-20 minutes. Their overall functioning in their creative, integrative and interactive expressions as an exclusive group in each separate sessions was 20 to 30 minutes The PANSS ratings are based on all information derived from the clinical interview, direct observation of the subjects and reports of primary care staff.

Each rating was assigned by first referring to the item definition to determine presence of a symptom. The severity of an item is then determined by deciding which anchoring point best described the subject's functioning, whether or not all components of the description are observed. The highest applicable rating was always assigned even if the subject meets criteria for the lower rating as well. White blood cell (WBC) count with differential and absolute neutrophil count (ANC) are monitored weekly to avoid hematologic adverse reactions, such as agranulocytosis. Paired sample t-tests were used to compare the total score improvement as well as score improvement in each of the three subscales (positive, negative and general psychopathology) at baseline and the end of 12weeks of treatment. Results are statistical significant if $\mathrm{P}<0.05$.

\section{RESULTS}

Final sample consisted of nineteen males and one female at the beginning of the study. However only nineteen clients finished the 12-week study (March 27th, 2006 to June 19th, 2006); one male client was transferred to another psychiatric facility before the week-4 assessment period. Final assessment thus only included data for 19 subjects who finished the study. Mean age of 39.5 years; range from $20-54$ years of age.

Clozapine ODT dosing ranged $300 \mathrm{mg}-900 \mathrm{mg}$ daily throughout the study period. $35 \%$ of subjects were on clozapine ODT as monotherapy. Other concurrent antipsychotic medications include ziprasidone, quetiapine, risperidone, olanzapine, aripiprazole, haloperidol, and chlorpromazine. None of the subject experienced agranulocytosis during the 6-week study period. One subject developed seizure during week-8 resulted in the dose reduction of study medication from $900 \mathrm{mg}$ to 600 mg daily.

\begin{tabular}{|l|l|}
\hline \multicolumn{2}{|l|}{ Table 2: Sample demographics: } \\
\hline Gender & $\begin{array}{l}19 \text { male ; } \\
\text { female }\end{array}$ \\
\hline Average age (N=20) & 39.5 years old \\
\hline $\begin{array}{l}\text { Average daily dose, } \\
\text { baseline ( } \mathrm{N}=20)\end{array}$ & $432.50 \mathrm{mg}$ \\
\hline $\begin{array}{l}\text { Average daily dose, at } \\
12-w e e k(\mathrm{~N}=19)\end{array}$ & $415.79 \mathrm{mg}$ \\
\hline $\begin{array}{l}\text { FazaClo } \\
\text { ODT) only (Clozapine }(\mathrm{N}=20)\end{array}$ & $35 \%$ (7 subjects) \\
\hline
\end{tabular}

Improvement in mean PANSS scores was observed in all three categories across the 12-week study period (Table 3). Paired sample t-tests showed statistically significant differences in all three scales and the total score between baseline and at week- 6 (Table 3).Compared to baseline, at week-12, the average reduction in Positive scale was $4.000 \pm$ 2.828 points, $4.947 \pm 3.341$ points in Negative scale, and $7.842 \pm 5.833$ points in General psychopathology scale (Table 4). Two subjects were discharged at week-12, and one subject was planning to be discharged shortly after reaching acceptable, stable clinical improvement.

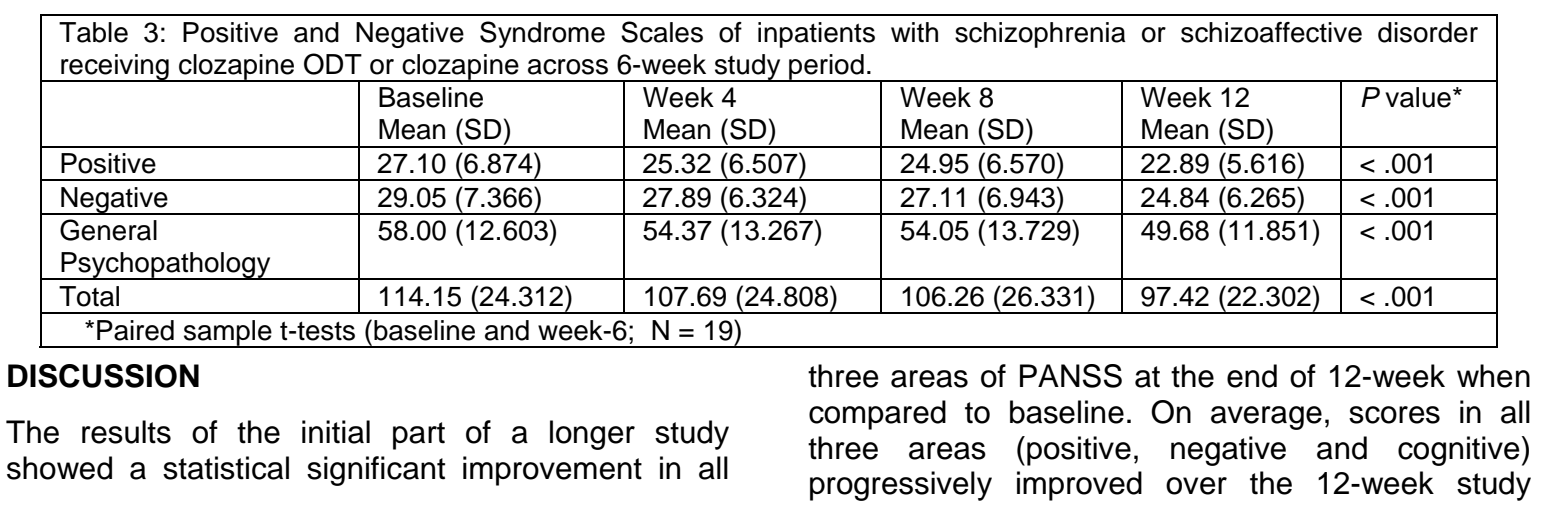


period. A greater improvement in negative scale compared to the positive scale was observed during the 6-week study period (-4.947 vs. -4.000). Negative syndrome is characterized by deficits in cognitive, affective, and social functions, including blunting of affect and passive withdrawal. This observation concurs with the current understanding of the clinical benefit of clozapine and other atypical antipsychotics, that in addition to improving positive and negative symptoms of schizophrenia (ex: delusion, hallucination, paranoia, etc.), these medications are effective in improving cognitive symptoms including their creative expressions and overall quality of life as their compliance are ensured.

\begin{tabular}{|l|l|l|}
\hline \multicolumn{3}{|l|}{$\begin{array}{l}\text { Table 4: Average reduction in positive, negative } \\
\text { and general psychopathology scales. }\end{array}$} \\
\hline & $\begin{array}{l}\text { Average } \\
\text { reduction }\end{array}$ & SD \\
\hline Positive & 4.000 & 2.828 \\
\hline Negative & 4.947 & 3.341 \\
\hline General Psychopathology & 7.842 & 5.833 \\
\hline Total & 16.789 & 9.378 \\
\hline
\end{tabular}

The greater improvement in negative symptoms, including cognitive functions, observed in this study is in accordance with results of some previous studies. A study done on subjects with schizophrenia or schizoaffective disorder by Volavka et $\mathrm{al}^{5}$ in 2002 comparing clozapine, olanzapine, risperidone and haloperidol showed that clozapine was the most effective treatment for negative symptoms. Lindemayer et $\mathrm{al}^{4}$ (1994) showed improvement in all three categories of PANSS in 12-weeks treatment period in treatmentrefractory schizophrenics with significant negative symptoms while on clozapine.

The study did not exclude subjects who were on other antipsychotic medications (in addition to clozapine ODT); the effect of other concurrent antipsychotic medications could have compounded the results of the study. However, it is a common, clinical practice for patients with schizophrenia or schizoaffective disorder to be on more than one antipsychotic. Clozapine usually is added as a last option to control psychotic symptoms or negative symptoms. This was an open-label study such that the clinical interviewers/investigators were not blinded to the dosage of study medications the subjects were using. It would be very difficult to blind the interviewers/investigators since one of them was the facility psychiatrist.

Clinical relevance and importance of current study: Unlike previous studies, clozapine ODT is used in here. Clozapine is typically used for refractory schizophrenia or schizoaffective disorder after other atypical antipsychotics, so its clinical effect on positive and negative symptoms, including cognition, is emphasized in the study. Primary measure of efficacy is the improvement in total PANSS score after twelve weeks of clozapine ODT treatment, including total score, as well as positive, negative and cognition (or general psychopathology) subscales in the study.

\section{CONCLUSIONS}

The present study used PANSS as an outcome measuring tool to evaluate the effect of clozapine ODT in patients with schizophrenia and schizoaffective disorder. The results of the 12-week preliminary study period showed statistically significant improvement in total score as well as in positive, negative and general psychopathology scales. The statistically significant improvement in PANSS further validates the clinical benefit of clozapine in treating refractory schizophrenia. Clozapine is typically reserved as treatment resistant schizophrenia due its potential risk of inducing agranulocytosis, so patients usually are given clozapine after they have only responded minimally to other antipsychotics. The promising results of the study confer hope to those refractoryschizophrenic patients and their families, in that, clozapine can help to improve positive and negative symptoms, and more importantly, cognition (creativity and expression). With improved cognition, patients can function more normally and more independently in society.

\section{ACKNOWLEDGEMENT}

The authors would like to thank the following people for their support of this project:

- Alamo Pharmaceutical and Ms. Cheryl Eakin for their grant for this study.

- Ryan Quist, Ph.D. for his statistical expertise.

\section{References}

1. Lexi-Comp. UpToDate®: "Clozapine: Drug information.".

2. Alamo Pharmaceuticals. FazaClo® General Information. http://www.fazaclo.com/Generallnfo.asp. (Accessed 03/02/2006)

3. Kay SR, Fiszbein A, Opler LA. The Positive and Negative Syndrome Scale (PANSS) for schizophrenia. Schizophrenia Bulletin 1987; 2:261-276.

4. Lindenmayer J, Grochowski S, Mabugat L. Clozapine effects on Positive and Negative Symptoms: A six-month trial in treatment-refractory schizophrenics. J Clin Psychopharmacol 1994; 14:201-4.

5. Volavka J, Czobor P, Sheitman B, Lindenmayer J, Citrome L, McEvoy JP, Cooper TB, Chakos M, Lieberman JA. Clozapine, olanzapine, risperidone, and haloperidol in the treatment of patients with chronic schizophrenia and schizoaffective disorder. Am J Psychiatry 2002; 159:255-62. 